\title{
Performance Evaluation of Extended Aeration-Based Sewage Treatment Plants at NCT of Delhi, India
}

\author{
SK Singh ${ }^{1}$, Vasudev Kapoor ${ }^{2}$, Karan Siriya ${ }^{3}$, Mehak Vashisth ${ }^{4}$ \\ Department of Environmental Engineering, Delhi Technological University, \\ Delhi-110042, India \\ sksinghdce@gmail.com1;vasudev.kapoor97@gmail.com2; \\ siriyakaran26@gmail.com3; mehakvashisth1999@gmail.com4 \\ D.O.I - 10.51201/JUSST/21/05/126 \\ http://doi.org/10.51201/JUSST/21/05126
}

\begin{abstract}
Due to urbanization and industrialization huge amount of wastewater is being generated, which is causing water pollution. Nowadays water pollution is a serious problem. The present study has been carried out to evaluate the efficiency of a waste water treatment plants with Extended Aeration Sludge Process (EASP). This has been done by examining the various physiochemical characteristics of wastewater (BOD, COD, TSS \& PO4), including a comparison of these characteristics at inlet and outlets of wastewater treatment plants and their variance over time. The examination of the competency of a technology is necessary for further optimization of the treatment units whilst complying with the Central Pollution Control Board (CPCB) requirements. In New Delhi's Extended Aeration Plants are not working to their peak potential, but have still been able to treat the significant wastewater effectively. The study implies that the effluent released into the Yamuna River would not contribute to the river's level of pollution.
\end{abstract}

Keywords: Extended Aeration Treatment Process, Performance Evaluation, Trickling Filter

\section{Introduction}

Wastewater is simply the water source of the society after it has been contaminated by a number of uses. During its use, the water supplied to the population receives a variety of chemical compounds and microbial flora in such a way that wastewater creates a polluting capacity and becomes a health and environmental threat (Sundara et al. 2010). In India, an enormous hole is seen between the amounts of wastewater which have been created, gathered, and treated. Additionally, existing wastewater treatment offices frequently work beneath plan principles. Thus, commonly this untreated wastewater is permitted to release either into the ground or normal streams (Gautam et al. 2013). Communicable diseases of the intestinal tract, such as cholera, typhoid, dysenteries, etc. and waterborne diseases may spread from this unregulated wastewater disposal, and thus prevention of communicable diseases and security of public health are the key objectives of sanitary wastewater disposal (Shan et al. 2021).

The huge volume of domestic and industrial wastewater generated in Delhi's National Capital Territory (NCT), which during it's passage through the NCT is the main cause of contamination of the Yamuna River (Shokeen et al. 2020). The most noticeable effect of urbanization is hydrologic transition (Kanakiya et al. 2014). The total amount of sewage produced in the city is evaluated to be much higher than the amount capacity of the Delhi Sewerage Treatment Plants (STPs) (Singh et al. 2020). Almost all of Delhi's treated and untreated waste discharged into the Yamuna River by means of various drains contributes $80 \%$ of the contamination of the Yamuna River (Gautam et al. 2013). Lakes play an important role in the world's ecosystem not only in-terms of providing a habitat for plants and animals but also are a cause for moderate hydrological extreme events (drought and floods), affect microclimate, improve the visual beauty of the landscape, and expand many recreational opportunities (Singh \& Deepika 2017). Thus, it is key to ensure the 
optimum treatment of waste-water prior to discharging the effluent into the river for the well-being of the living organisms. (Gupta et al. 2018)

The activated sludge method (ASP) and Trickling Filter are used in traditional biological wastewater treatment within aerobic conditions. The extended aeration sludge process (EATP), which is a variation of the traditional activated sludge process, is commonly used for the treatment of domestic wastewater (Singh et al. 2018). Figure 1 shows the process flow diagram of EATP. It is designed to have a much longer aeration time than the conventional activated sludge process (generally 18-24 hours) preceded by a 3-6 hour cycle for sludge and liquid separation in the final separating tank. It is constructed to provide an aeration time much longer than the traditional activated sludge process (usually 18-24 hours) followed by a 3-6 hour period in the final separating tank for liquid and sludge separation. The EATP flow scheme is similar to that of a fully mixed mechanism, except that the primary settlement is omitted (Shammari \& Shahalam 2019).

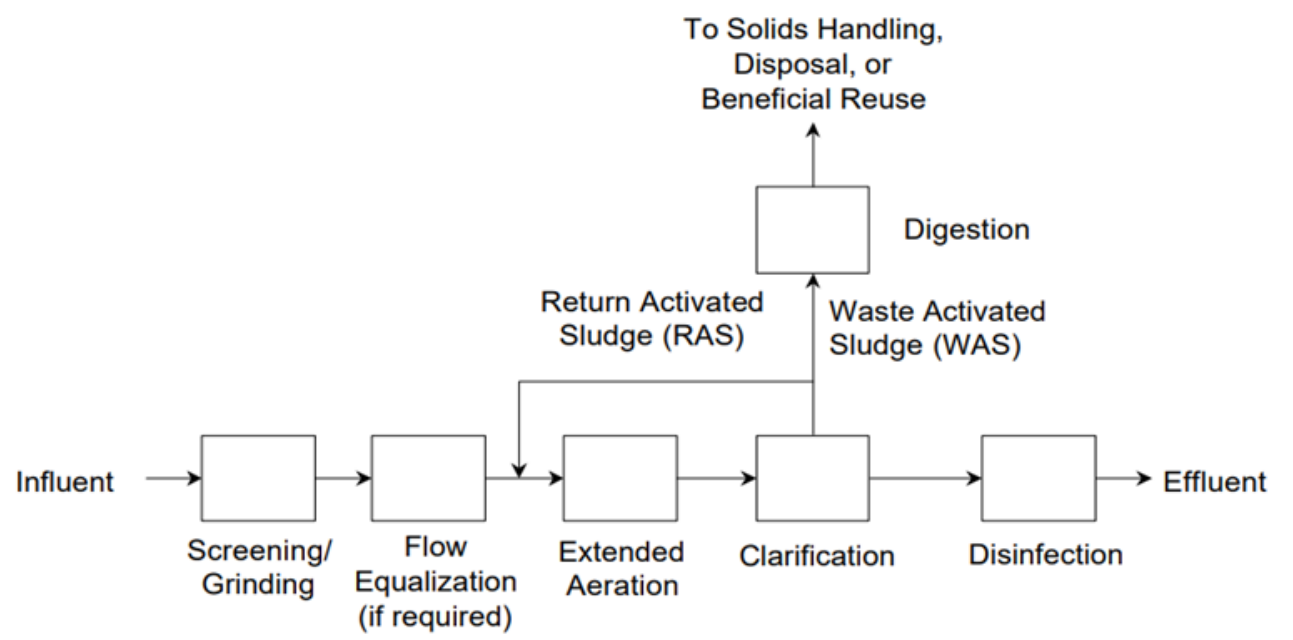

Figure 1. Process Flow Diagram for Extended Aeration Treatment Process

Performance evaluation is necessary to know existing effluent quality as well as the effect of influent characteristics variation on the efficiency of different treatment units. Water must be analyzed to assess its suitability for drinking, domestic use, industrial use, and agricultural use, among other things (Sharma et al. 2015). Chemical properties of the treated water determine its reuse in domestic, industrial or agricultural capacity. (Ankit \& Singh 2021)Therefore, in order to accomplish these capacities, the current treatment plant needs to be upgraded, which includes execution assessment to assess the potential for expansion or alteration of the process (Bhave et al. 2020). These performance assessment data can be given during the plan of the new treatment plant so that the treated wastewater should comply with the requirements laid down by the Central Pollution Control Board (CPCB report 2005). The proficiency of treatment plants treating sewage can be assessed by evaluating the concentration of pollutant within the inlet raw and treated water (Metcalf and Eddy 2003) and for that, measurement of physicochemical parameters is commonly preferred in order to determine the quality of influent and effluent from the sewage treatment plant (Bayo et al. 2016).

In lieu of the above facts, the present study is conducted to evaluate the performance of the sewage treatment plants using extended aeration, by analyzing different physiochemical characteristics of the sewage, which includes comparison of these characteristics at inlet \& outlets of STPs and their variation along a period of time.

\section{Materials \& Methods}

\subsection{Description of Study Area}


The study was carried out at all three sewage treatment plants that are based on extended aeration treatment process, located in Delhi (latitude/longitude $\left.28^{\circ} 38^{\prime} / 77^{\circ} 13^{\prime}\right)$ which is the Indian Capital \& in the north region of the subcontinent. The mean monthly temperature ranges from $14.3^{\circ} \mathrm{C}$ in the coldest month that is January, to about $34.5^{\circ} \mathrm{C}$ in the hottest month June. Table 1 shows the capacity (in MLD) and utilization of the STPs. Vasant Kunj's STP has 2 separate units (with 9.9 \&13.6 MLD capacities) and located in south side of the city. Location of the plants is shown in Figure 2. All the plants are managed \& organized by Delhi Jal Board and use extended aeration sludge process to biologically treat municipal wastewater. Most of the effluent part is discharged into Yamuna River via different drains.

Table 1. Salient Features of the Sewage Treatment Plants

\begin{tabular}{|c|c|c|c|c|c|c|}
\hline $\begin{array}{l}\text { S. } \\
\text { No. }\end{array}$ & Name of STP & $\begin{array}{c}\text { Design } \\
\text { Treatment } \\
\text { Capacity } \\
\text { (MLD) }\end{array}$ & $\begin{array}{c}\text { Utilization } \\
(\%)\end{array}$ & $\begin{array}{c}\text { Year of } \\
\text { Installation }\end{array}$ & $\begin{array}{c}\text { Managing } \\
\text { Agency }\end{array}$ & Discharge /Reuse \\
\hline \multirow{3}{*}{1.} & $\begin{array}{c}\text { Vasant Kunj's } \\
\text { STP }\end{array}$ & & & & & \\
\hline & $(1)$ & 9.9 & 54.5 & 1992 & \multirow{2}{*}{ Delhi Jal Board } & \multirow{2}{*}{$\begin{array}{c}\text { Partly to Sanjay } \\
\text { Van to Kushak } \\
\text { drain }\end{array}$} \\
\hline & (2) & 13.6 & 66.7 & 1998 & & \\
\hline 2. & Mehrauli's STP & 22.73 & 34 & 2003 & Delhi Jal Board & River Yamuna \\
\hline 3. & $\begin{array}{l}\text { Najafgarh's } \\
\text { STP }\end{array}$ & 22.73 & 24 & 2000 & Delhi Jal Board & $\begin{array}{l}\text { Najafgarh Drain } \\
\text { to Yamuna river }\end{array}$ \\
\hline
\end{tabular}

Source: Central Pollution Control Board (CPCB)

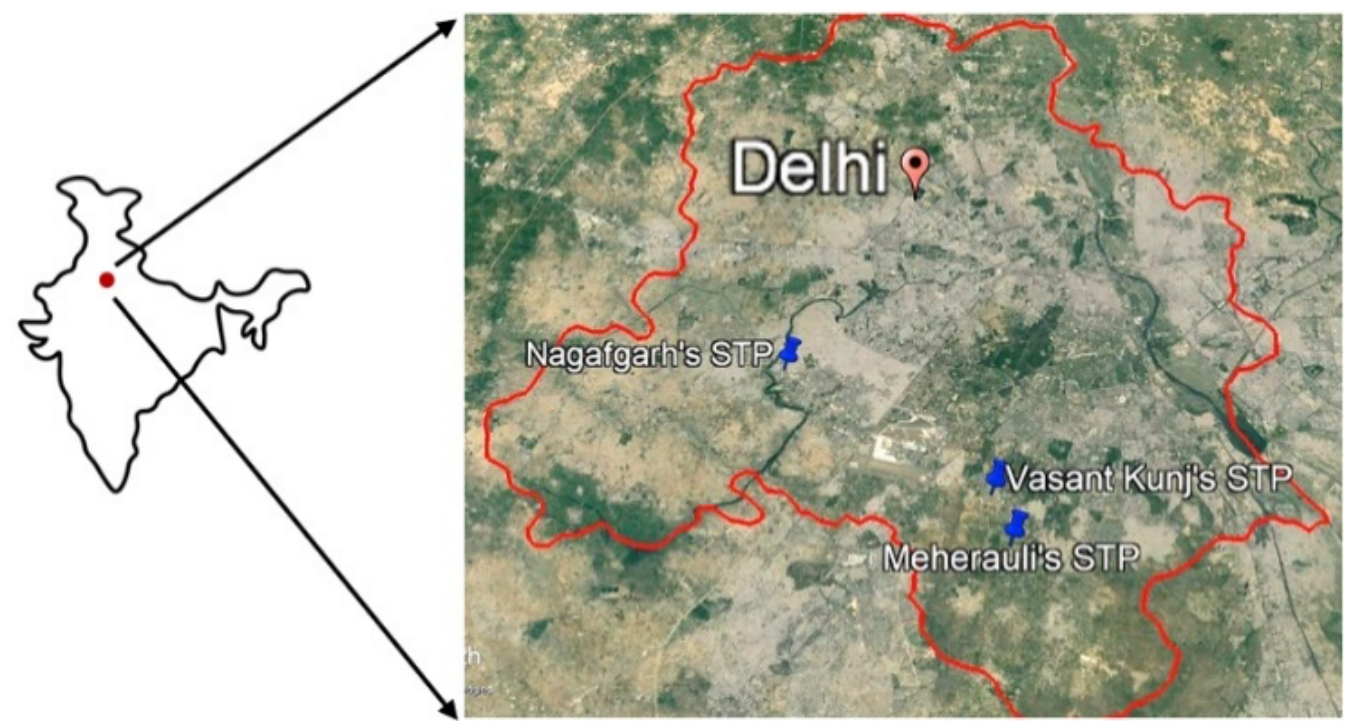

Figure 2. Study Map of STPs using EASP in Delhi

\subsection{Sampling \& Analysis}

The treatment efficiency of STPs was assessed on the basis of routine monitoring carried out during first three quarters of 2020 (January - September 2020, except April) in the first phase and the second phase includes the last quarter of 2020 and the first of 2021 (October 2020 - March 2021). The data was collected from DPCC official site. The grab samples of raw influent and effluent were collected on monthly basis at STPs within first couple of weeks of every month by Delhi Pollution Control Committee. Samples were analyzed for different parameters such as $\mathrm{pH}, \mathrm{BOD}, \mathrm{COD} \& \mathrm{TSS}$ based on standard 
methods for the examination of water and wastewater at DPCC lab, Kashmere Gate, Delhi, India. Performance assessment was carried out by comparing the concentrations of contaminants at the inlet and outlet of the treatment plants over a period of 14 months.

Table 2. Standards of Municipal Wastewater Effluent for discharge

\begin{tabular}{|c|c|}
\hline Parameters & Concenteration not to exceed \\
\hline $\mathrm{pH}$ & $5.5-9$ \\
\hline $\mathrm{TSS}$ & $10 \mathrm{mg} / 1$ \\
\hline $\mathrm{BOD}$ & $10 \mathrm{mg} / 1$ \\
\hline $\mathrm{COD}$ & $50 \mathrm{mg} / 1$ \\
\hline $\mathrm{PO}_{4}$ & $2 \mathrm{mg} / 1$ \\
\hline
\end{tabular}

\section{Results \& Discussion}

The samples were collected at inlet $\&$ outlet of the plants for a period of total 8 months, from January to March \& May to September 2020. The results for April 2020 are not considered for review and conclusion as the sampling was not possible due to the lockdown because of the Covid pandemic. Evaluation of the efficiency output of the plant was conducted with regard to the quality of the effluent. A study suggests that the common productivity marker used to measure the overall performance of the various plants in terms of average TSS, COD, BOD and phosphate removal efficiencies. In the same way, the performance of plants is usually calculated in terms of elimination of organic matter.

\section{1. $\mathbf{p H}$}

Determination of $\mathrm{pH}$ is one of the key objectives for wastewater treatment and its variation over study period is provided in Table 3. The $\mathrm{pH}$ of water varies greatly with time period due to interaction with biological activity, air and temperature changes. Important $\mathrm{pH}$ changes occur as a result of industrial waste disposal. The $\mathrm{pH}$ specifically influences the effectiveness of the secondary treatment process since the survival of most biological life depends on essential and slight $\mathrm{pH}$ extend. The $\mathrm{pH}$ of the effluent decides its functionality for a number of purposes. As a very high or low $\mathrm{pH}$, it is toxic to marine organisms as well as affects the solubility of basic elemental and chemical contaminants.

In the current study, the $\mathrm{pH}$ value of influent varies between 7 to 8.3 (max in June at Najafgarh \& min in Aug at Vasant Kunj 2nd unit), while for effluent from 7.2 to 8.1 (max in June at Najafgarh \& min in Sept at Vasant Kunj 1st unit). Figure 3 shows the inlet \& outlet comparison of $\mathrm{pH} \&$ indicates the alkaline nature of the effluent. Some studies have also reported an increment in the alkaline nature of wastewater after treatment.

\subsection{Total Suspended Solids}

TSS is an indication of wastewater's floating particulate content and is an estimate of waste water's quality. Many industrial activities lead to water turbidity and adjustable solids with resulting bottom deposits that impact aquatic life at various degrees of severity. The transmission of light can be limited by fine particulate matter that remains in suspension, thereby restricting the development of attached bottom aquatic flaura as well as floating or swimming algal types that are capable of photosynthesis and rely on light for their lives.

Table 4 shows the TSS value of all the treatment plants during both study periods and average values of influent \& effluent are $229.25 \mathrm{mg} / 1 \& 31.26 \mathrm{mg} / \mathrm{l}$ respectively in the first phase. Average TSS removal efficiency is maximum (90.4\%) of Vasant Kunj's 1st unit as compared to other plants using extended aeration process. Every plant is not able to meet the CPCB standards for sewage effluent to discharge as mentioned in Table 2 .

In the second phase, the maximum TSS was observed at Vasant Kunj(2) in November 2020 and lies between $104 \mathrm{mg} / \mathrm{L}$ and 372mg/L. Vasant Kunj (1), Mehrauli and Najafgarh 
plants have shown increase in efficiency, the greatest change in efficiency has been at Mehrauli with a $10.2 \%$ increase. Vasant Kunj (2) has a net $0.6 \%$ decrease in efficiency.

\subsection{Biochemical Oxygen Demand}

The BOD removal is the efficiency indicator of biological treatment processes and is the most commonly used criteria for calculating the quality of wastewater. The average BOD of the influent during the first phase of the study period is maximum $(187.5 \mathrm{mg} / \mathrm{l})$ of Vasant Kunj's 1st unit and minimum (136.4 mg/l) of Mehrauli STP while effluent is maximum $(25.8 \mathrm{mg} / \mathrm{l})$ of Najafgarh STP \& minimum $(17.1 \mathrm{mg} / \mathrm{l})$ of Vasant Kunj's 2nd unit (Table 5, Figure5). BOD removal efficiency of Vasant Kunj STPs is maximum while Mehrauli STP is $83.9 \%$ and Najafgarh STP is $82 \%$ (Table 8). BOD of the effluent did not meet the standards as in Table 2 except Vasant Kunj's 1st unit in Sept and Vasant Kunj's 2nd unit in May 2020. BOD removal efficiency of sewage is maximum of treatment plants using extended aeration process in comparison of plants using other methods in Delhi.

In the second phase, the maximum BOD observed is at Vasant Kunj(1) in November 2020 with its value at the plant inlet $177.8 \mathrm{mg} / \mathrm{L}$ and the outlet demonstrating $15.8 \mathrm{mg} / \mathrm{L}$. Table illustrates that Vasant Kunj(1) has the highest percentage removal with a value of $91.1 \%$ and the lowest value has been observed in the case of Najafgarh with percentage removal of $84.95 \%$. Vasant Kunj (1), Mehrauli and Najafgarh plants have shown increase in efficiency, the greatest change in efficiency has been at Mehrauli with a 7.9\% increase. Vasant Kunj (2) has a net $1.3 \%$ decrease in efficiency.

\subsection{Chemical Oxygen Demand}

COD is the oxygen amount retained by the chemical catalyzation of organic and inorganic matter and is essentially utilized to evaluate the capacity of organic substances to assimilate oxygen in water. High levels of COD in wastewater contribute to a significant loss of oxygen until it is released into the bodies of water and adversely affects the biota. The shrink can be associated with digestion processes and aeration. The general trend is COD being higher than BOD since more compounds can be chemically oxidized than can biologically oxidized. In first phase of the study, COD of influent varies from $120 \mathrm{mg} / 1$ to $860 \mathrm{mg} / \mathrm{l}$, where maximum in Jan \& minimum in Jun at Vasant Kunj's 2nd unit and effluent varies from $12 \mathrm{mg} / 1$ to $168 \mathrm{mg} / \mathrm{l}$ (Table 6). All plants are meeting the COD effluent standards in most of the cases.

In the second phase, the maximum COD removal efficiency observed is at Vasant Kunj(1) with a percentage of 86.1. Table shows that the efficiency of COD removal shows similar values in the case of Vasant Kunj(2) and Mehrauli whereas Najafgarh plant has shown the least value of 78.6\%. The efficiency at Vasant Kunj (1), Vasant Kunj (2) and Najafgarh has decreased by 5.3\%, 4.3\% and 3.3\% respectively, however, Mehrauli has outperformed by showing an increase of $2.3 \%$.

\subsection{Phosphate}

Phosphate is extracted from human and domestic detergents and soaps dependent on phosphate in sewage effluents. Phosphorous is among the critical elements for algae formation, and in order to avoid toxic algae blooms, its content in wastewater discharges must be controlled/reduced. The average concentration of dissolved phosphate in wastewater before treatment varies from $7-8 \mathrm{mg} / \mathrm{l}$ and after treatment varies from 0.9-1.7 $\mathrm{mg} / \mathrm{l}$, hence meeting the CPCB standards (Table 7, Fig. 3). The maximum phosphate removal efficiency is $87.2 \%$ of Vasant Kunj's 2nd unit and minimum is $76.2 \%$ of Najafgarh STP during the first phase of the study (Table 8).

In the second phase, the maximum PO4 observed is at the plant inlet of Vasant Kunj (2) in December 2020 whereas phosphate removal at the inlet of the same shows a value of 1.9. Inspite of the above plant having the highest efficiency, the overall percentage removal of Vasant Kunj (2) is the least. The highest has been observed in the case of Vasant Kunj (1) with a value of 89.8. Vasant Kunj (1), Mehrauli and Najafgarh plants have shown increase in efficiency by $6.3 \%, 6.3 \%, 9.6 \%$ respectively, whereas Vasant Kunj (2) has a net $4.6 \%$ decrease in efficiency. 


\subsection{Comparison Between the First and Second Phase of the Study}

The comparison between the two phases showcases the efficiency constraints due to the COVID-19 Pandemic. It is observed that the efficiency of the plant has shown an increasing trend along the physiochemical parameters of TSS, BOD and Phosphates at Vasant Kunj (1), Mehrauli and Najafgarh with a mean increase of $6.2 \%$ in TSS, $4.2 \%$ in BOD and $7.4 \%$ in Phosphates.

COD efficiency observed has decreased at Vasant Kunj (1), Vasant Kunj (2) and Najafgarh with only Mehrauli showing a $2.3 \%$ increase.

Table 3. Inlet \& outlet pH values of STPs during study period

\begin{tabular}{|c|c|c|c|}
\hline \multicolumn{2}{|c|}{ STP/Month } & Jan-Sept & Oct-Mar \\
\hline \multirow{2}{*}{ Vasant Kunj (1) } & Inlet & 7.42 & 7.18 \\
\cline { 2 - 4 } & Outlet & 7.60 & 7.32 \\
\hline \multirow{2}{*}{ Vasant Kunj (2) } & Inlet & 7.44 & 7.23 \\
\cline { 2 - 4 } & Outlet & 7.63 & 7.12 \\
\hline \multirow{2}{*}{ Mehrauli } & Inlet & 7.53 & 7.27 \\
\cline { 2 - 4 } & Outlet & 7.67 & 7.36 \\
\hline \multirow{2}{*}{ Najafgarh } & Inlet & 7.52 & 7.07 \\
\cline { 2 - 4 } & Outlet & 7.64 & 7.30 \\
\hline
\end{tabular}

Table 4. Inlet \& outlet TSS values (mg/l) of STPs during study period

\begin{tabular}{|c|c|c|c|}
\hline \multicolumn{2}{|c|}{ STP/Month } & Jan-Sept & Oct-Mar \\
\hline \multirow{2}{*}{ Vasant Kunj (1) } & Inlet & 266.0 & 315.20 \\
\cline { 2 - 4 } & Outlet & 25.6 & 24.80 \\
\hline \multirow{2}{*}{ Vasant Kunj (2) } & Inlet & 238.8 & 258.67 \\
\cline { 2 - 4 } & Outlet & 25.9 & 29.33 \\
\hline \multirow{2}{*}{ Mehrauli } & Inlet & 196.5 & 184.00 \\
\cline { 2 - 4 } & Outlet & 34.0 & 16.33 \\
\hline \multirow{2}{*}{ Najafgarh } & Inlet & 215.8 & 315.33 \\
\cline { 2 - 4 } & Outlet & 39.6 & 40.67 \\
\hline
\end{tabular}

Table 5. Inlet \& outlet BOD values (mg/l) of STPs during study period

\begin{tabular}{|c|c|c|c|}
\hline \multicolumn{2}{|c|}{ STP/Month } & Jan-Sept & Oct-Mar \\
\hline \multirow{2}{*}{ Vasant Kunj (1) } & Inlet & 187.5 & 177.80 \\
\cline { 2 - 4 } & Outlet & 18.4 & 15.80 \\
\hline \multirow{2}{*}{ Vasant Kunj (2) } & Inlet & 158.0 & 154.67 \\
\cline { 2 - 4 } & Outlet & 17.1 & 18.50 \\
\hline \multirow{2}{*}{ Mehrauli } & Inlet & 136.4 & 119.17 \\
\cline { 2 - 4 } & Outlet & 22.0 & 11.25 \\
\hline \multirow{2}{*}{ Najafgarh } & Inlet & 142.8 & 152.83 \\
\cline { 2 - 4 } & Outlet & 25.8 & 23.00 \\
\hline
\end{tabular}


Table 6. Inlet \& outlet COD values ( $\mathrm{mg} / \mathrm{l}$ ) of STPs during study period

\begin{tabular}{|c|c|c|c|}
\hline \multicolumn{2}{|c|}{ STP/Month } & Jan-Sept & Oct-Mar \\
\hline \multirow{2}{*}{ Vasant Kunj (1) } & Inlet & 499.5 & 455.20 \\
\cline { 2 - 4 } & Outlet & 45.5 & 63.20 \\
\hline \multirow{2}{*}{ Vasant Kunj (2) } & Inlet & 405.5 & 440.33 \\
\cline { 2 - 4 } & Outlet & 48.0 & 68.67 \\
\hline \multirow{2}{*}{ Mehrauli } & Inlet & 354.5 & 299.56 \\
\cline { 2 - 4 } & Outlet & 62.0 & 46.67 \\
\hline \multirow{2}{*}{ Najafgarh } & Inlet & 388.5 & 383.17 \\
\cline { 2 - 4 } & Outlet & 72.5 & 82.00 \\
\hline
\end{tabular}

Table 7. Inlet \& outlet PO4 values $(\mathrm{mg} / \mathrm{l})$ of STPs during study period

\begin{tabular}{|c|c|c|c|}
\hline \multicolumn{2}{|c|}{ STP/Month } & Jan-Sept & Oct-Mar \\
\hline \multirow{2}{*}{ Vasant Kunj (1) } & Inlet & 8.0 & 13.96 \\
\cline { 2 - 4 } & Outlet & 1.2 & 1.42 \\
\hline \multirow{2}{*}{ Vasant Kunj (2) } & Inlet & 7.2 & 10.82 \\
\cline { 2 - 4 } & Outlet & 0.9 & 1.82 \\
\hline \multirow{2}{*}{ Mehrauli } & Inlet & 7.3 & 11.62 \\
\cline { 2 - 4 } & Outlet & 1.2 & 1.33 \\
\hline \multirow{2}{*}{ Najafgarh } & Inlet & 7.0 & 13.12 \\
\cline { 2 - 4 } & Outlet & 1.7 & 2.17 \\
\hline
\end{tabular}

Table 8. STP's average removal efficiencies for different parameters in Period 1

\begin{tabular}{|c|c|c|c|c|c|c|c|c|c|c|c|c|}
\hline \multirow{2}{*}{ STP/Parameters } & \multicolumn{3}{|c|}{ TSS (mg/l) } & \multicolumn{3}{|c|}{ BOD (mg/l) } & \multicolumn{3}{|c|}{ COD (mg/l) } & \multicolumn{3}{|c|}{ PO4 (mg/l) } \\
\hline & Inlet & Outlet & $\%$ removal & Inlet & Outlet & $\%$ removal & Inlet & Outlet & $\%$ removal & Inlet & Outlet & $\%$ removal \\
\hline $\begin{array}{l}\text { VASANT } \\
\text { KUNJ(1) } \\
\end{array}$ & 266.0 & 25.6 & 90.4 & 187.5 & 18.4 & 90.2 & 499.5 & 45.5 & 90.9 & 8.0 & 1.2 & 84.5 \\
\hline $\begin{array}{l}\text { VASANT } \\
\text { KUNJ(2) }\end{array}$ & 238.8 & 25.9 & 89.2 & 158.0 & 17.1 & 89.2 & 405.5 & 48.0 & 88.2 & 7.2 & 0.9 & 87.2 \\
\hline MEHRAULI & 196.5 & 34.0 & 82.7 & 136.4 & 22.0 & 83.9 & 354.5 & 62.0 & 82.5 & 7.2 & 1.2 & 83.3 \\
\hline NAJAFGARH & 215.8 & 39.6 & 81.7 & 142.8 & 25.8 & 82.0 & 388.5 & 72.5 & 81.3 & 7.0 & 1.6 & 76.2 \\
\hline
\end{tabular}

Table 9. STP's average removal efficiencies for different parameters in Period 2

\begin{tabular}{|c|c|c|c|c|c|c|c|c|c|c|c|c|}
\hline \multirow{2}{*}{ STP/Parameters } & \multicolumn{3}{|c|}{ TSS (mg/l) } & \multicolumn{3}{|c|}{ BOD (mg/l) } & \multicolumn{3}{|c|}{ COD (mg/l) } & \multicolumn{3}{|c|}{ PO4 (mg/l) } \\
\hline & Inlet & Outlet & $\%$ removal & Inlet & Outlet & $\%$ removal & Inlet & Outlet & $\%$ removal & Inlet & Outlet & $\%$ removal \\
\hline $\begin{array}{l}\text { VASANT } \\
\text { KUNJ(1) }\end{array}$ & 315.2 & 24.8 & 92.1 & 177.8 & 15.8 & 91.1 & 455.2 & 63.2 & 86.1 & 14.0 & 1.4 & 89.8 \\
\hline $\begin{array}{l}\text { VASANT } \\
\text { KUNJ(2) }\end{array}$ & 258.7 & 29.3 & 88.7 & 154.7 & 18.5 & 88.0 & 440.3 & 68.7 & 84.4 & 10.8 & 1.8 & 83.2 \\
\hline MEHRAULI & 184.0 & 16.3 & 91.1 & 119.2 & 11.3 & 90.6 & 299.6 & 46.7 & 84.4 & 11.6 & 1.3 & 88.6 \\
\hline NAJAFGARH & 315.3 & 40.7 & 87.1 & 152.8 & 23.0 & 85.0 & 383.2 & 82.0 & 78.6 & 13.1 & 2.2 & 83.5 \\
\hline
\end{tabular}



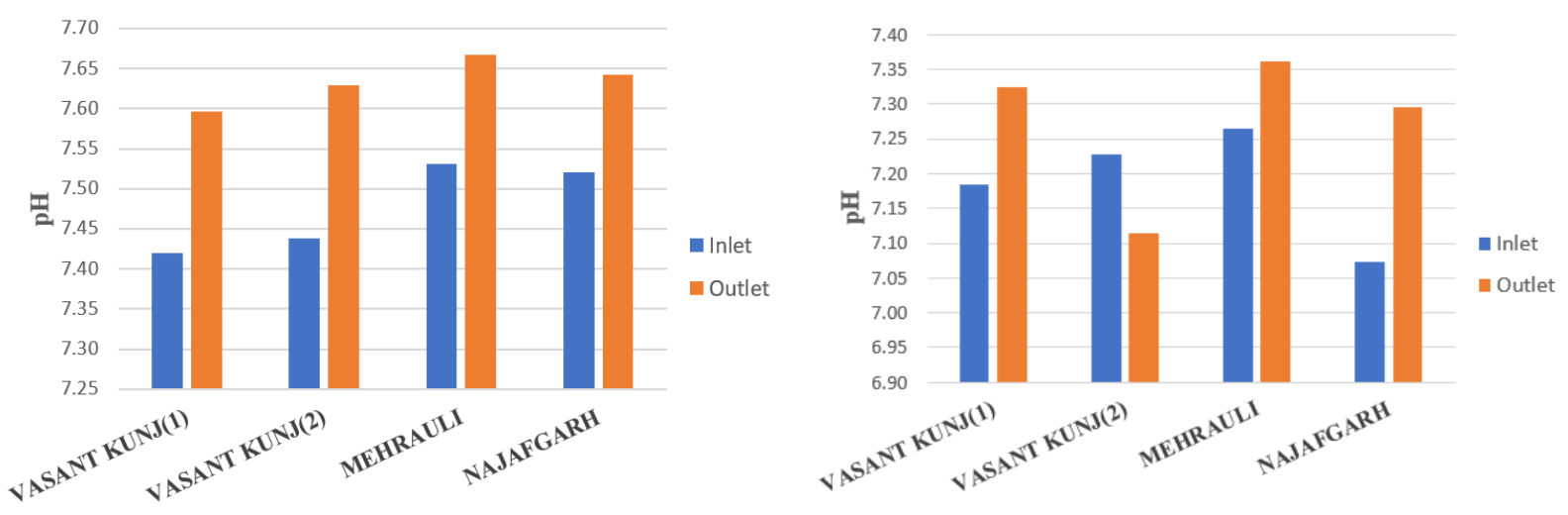

Figure 3. Average inlet \& outlet pH values of STPs in Period $1 \& 2$
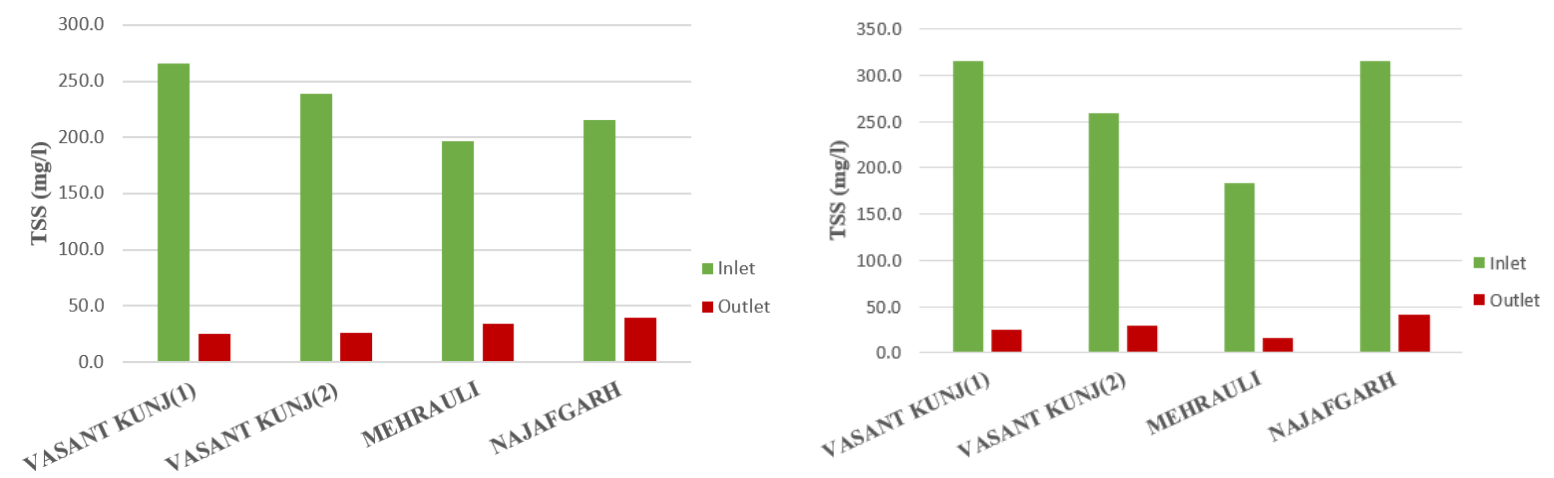

Figure 4. Average inlet \& outlet TSS values of STPs in Period 1\&2
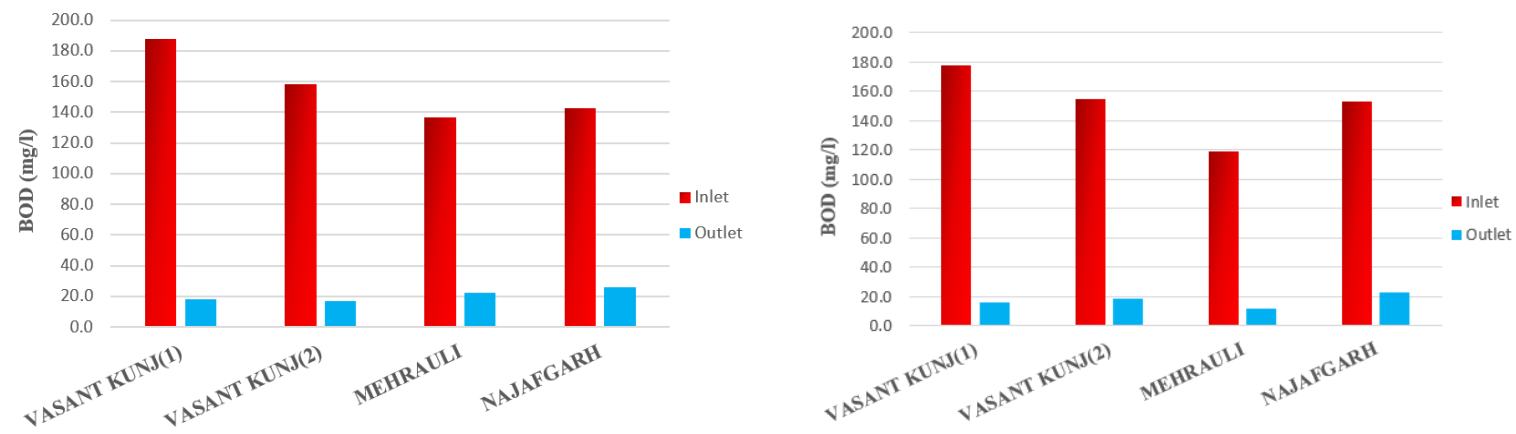

Figure 5. Average inlet \& outlet BOD values of STPs in Period $1 \& 2$ 

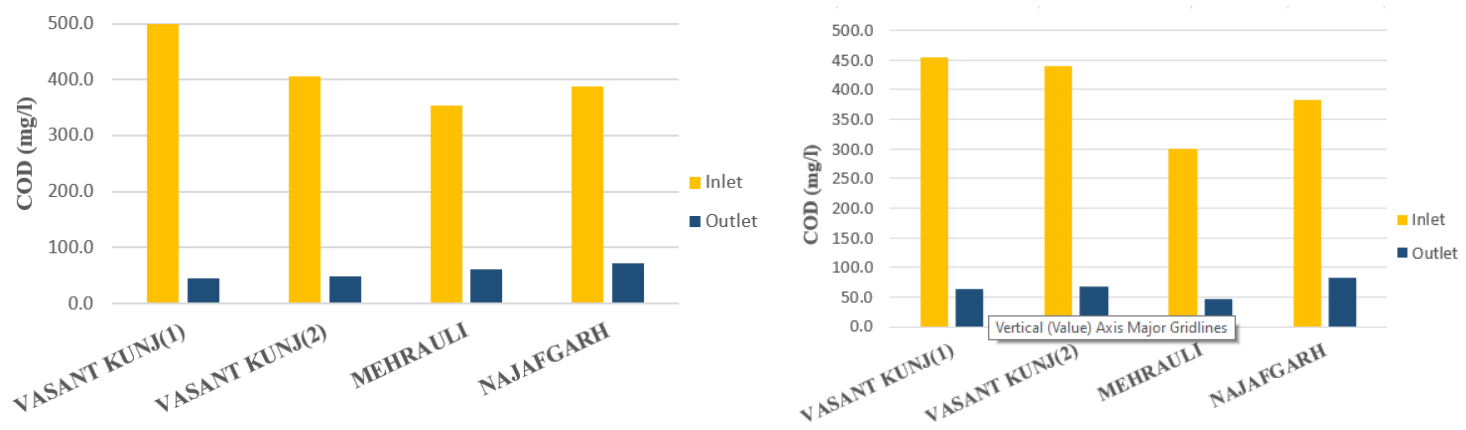

Figure 6. Average inlet \& outlet COD values of STPs in Period 1\&2
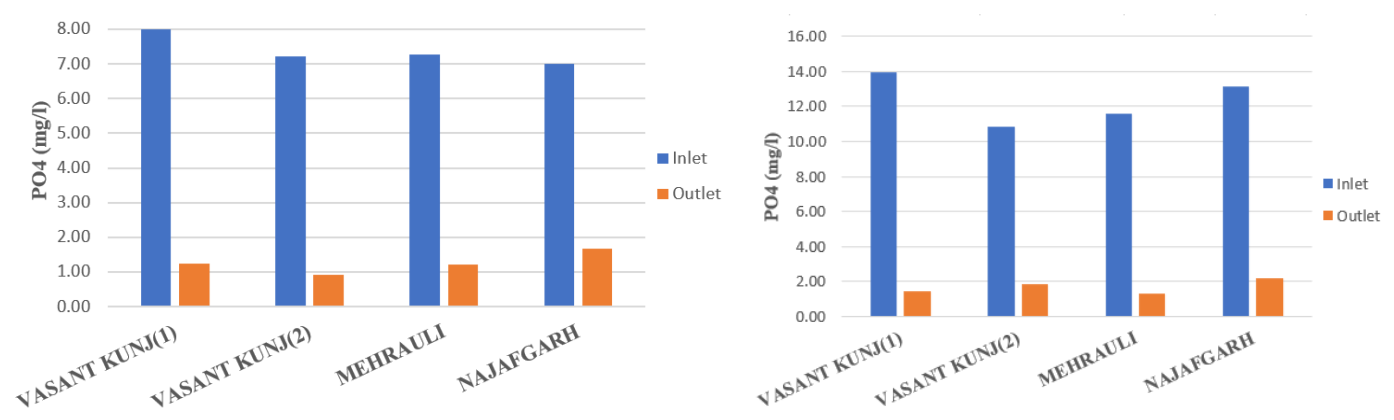

Figure 7. Average inlet \& outlet PO4 values of STPs in Period $1 \& 2$

\section{Conclusion}

In the present study, wastewater treatment plants with extended aeration as a biological treatment system has been considered for performance assessment. The data for April 2020 are not considered for review and conclusion as the sampling was not possible due to the lockdown because of the Covid pandemic. The influent to STPs is observed medium to high in strength. The study has been able to demonstrate that these treatment plants greatly eliminated the unacceptable physiochemical properties of wastewater before its discharge into the river Yamuna. In this study, the $\mathrm{pH}$ value of the wastewater after treatment lies in the alkaline zone. The BOD and COD values have been diminished to a large degree, which indicates the expulsion of organic matter. The rate of phosphate removal was found to be relatively low compared to other parameters. The removal of TSS is also achieved to a great degree but not as per the CPCB standards for disposal. Vasant Kunj's both units outperformed in all physiochemical parameters of sewage treatment than other two extended aeration-based plants. However, Mehrauli has shown an overall increase in efficiency across the two study phases. It is observed that the efficiency of the plant has shown an increasing trend along the physiochemical parameters of TSS, BOD and Phosphates at Vasant Kunj (1), Mehrauli and Najafgarh. The cause for such increase is attributed to the plants functioning at optimum manpower which has greatly improved the efficiency of the plant.

COD efficiency observed has decreased at Vasant Kunj (1), Vasant Kunj (2) and Najafgarh. This can be attributed to the proximal Industrial Activity which has increased post an initial decline.

Extended Aeration Plants in New Delhi are not running to their optimum capacity but were still able to effectively treat the influent wastewater. This treatment also ensures that the effluent let out into the River Yamuna will not add to the pollution levels of the River. Recycling of the treated wastewater into various other uses such as agriculture can also be achieved due to the treatment of phosphate levels well below the threshold limit. 


\section{References}

Akan J.C., Abdulrahman F.I., Dimari G.A., Ogugbuaja V.O. (2008). Physicochemical determination of pollutants in wastewater and vegetable samples along the Jakara wastewater channel in Kano Metropolis, Kano State, Nigeria. Eur J Sci Res, 23(1):122-133.

Al-Shammari, S. B., \& Shahalam, A. (2019). Assessment of Extended Aeration Sludge Process in Jahra Wastewater Treatment Plant-Kuwait. International Journal of Environmental Science and Development, 10(2), 66-69.

Ankit, Singh S.K. (2021) An Overview of Performance Evaluation of Sewage Treatment Plants, Journal of USS \& T, Vol. 23 No.4, pp 306-316

APHA, AWWA, WPCF (1998). Standard Methods For The Examination Of Water And Wastewater. American Public Health Association. Washington, D.C., USA.

Bayo, J., \& López-Castellanos, J. (2016). Principal factor and hierarchical cluster analyses for the performance assessment of an urban wastewater treatment plant in the Southeast of Spain. Chemosphere, 155, 152-162.

Bhave, P. P., Naik, S., \& Salunkhe, S. D. (2020). Performance Evaluation of Wastewater Treatment Plant. Water Conservation Science and Engineering.

Colmenarejo, M. F., Rubio, A., Sánchez, E., Vicente, J., García, M. G., \& Borja, R. (2006). Evaluation of municipal wastewater treatment plants with different technologies at Las Rozas, Madrid (Spain). Journal of Environmental Management, 81(4), 399-404.

CPCB, Central Pollution Control Board (2005). Performance status of common effluent treatment plants in India.

CPHEEO, Central Public Health and Environmental Engineering Organization (1993). Manual on sewerage and sewage treatment (2nd ed.), New Delhi.

DPCC, Delhi Pollution Control Committee (2020). www.dpcc.delhigovt.nic.in

Gautam, S. K., Sharma, D., Tripathi, J. K., Ahirwar, S., \& Singh, S. K. (2012). A study of the effectiveness of sewage treatment plants in Delhi region. Applied Water Science, 3(1), 57-65.

Jamwal, P., Mittal, A. K., \& Mouchel, J.-M. (2008). Efficiency evaluation of sewage treatment plants with different technologies in Delhi (India). Environmental Monitoring and Assessment, 153(1-4), 293-305.

JN Sharma, Raj S. Kanakiya, S.K. Singh (2015), Limnological study of water quality parameters of Dal lake, India, International Journal of Innovative Research in Science, Engineering and Technology, 4(2): 380-386

Kumar, P. R., Pinto, L. B., \& Somashekar, R. (2010). Assessment of the efficiency of sewage treatment plants: a comparative study between Nagasandra and Mailasandra sewage treatment plants. Kathmandu University Journal of Science, Engineering and Technology, 6(2).

Maharia, S., \& Srivastava, A. (2014). Influence of seasonal variation on concentration of fungal bioaerosol at a sewage treatment plant (STP) in Delhi. Aerobiologia, 31(2), 249-260.

Mehta Dhruv, Mazumdar Siddharth and Singh S.K. (2015). Magnetic adsorbents for the treatment of water/wastewater-A review. Journal of Water Process Engineering, 7(), 244-265.

Metcalf and Eddy (2003). Waste Water Engineering - Treatment, Disposal and Reuse, 4th edn. Tata McGraw Hill, New York.

Morrison, G., Fatoki, O., Persson, L. and Ekberg, A., (2001). Assessment of the impact of point source pollution from the Keiskammahoek Sewage Treatment Plant on the Keiskamma River - $\mathrm{pH}$, electrical conductivity, oxygen- demanding substance (COD) and nutrients. Water SA, 27(4).

Ogunfowoka A.O., Okoh E.K., Adenuga A.A. \& Asubiojo O.I. (2004). An Assessment of the Impact of Point Source Pollution from a University Sewage Treatment Oxidation 
Pond on a Receiving Stream-A Preliminary Study. Journal of Applied Sciences, 5(1), pp.36-43.

Raj Shailesh Kanakiya, SK Singh, JN Sharma (2014) Determining the Water Quality Index of an Urban Water Body Dal Lake, Kashmir, India, IOSR Journal of Environmental Science, Toxicology and Food Technology; 8 (12): 64-71

Rustogi, P. and Singh., S.K. (2017). Revival and rejuvenation strategy of water bodies in a metropolitan city: a case study of Najafgarh lake, Delhi, India. International Journal of Advanced Research, 5(2), pp.189-195.

Salunke K. A., Bhave P. P. \& Mata M. D. (2014). Performance status of common effluent treatment plant at Dombivali CEPT. International Journal of Research in Engineering and Technology, 03(21), pp.48-52.

Shan, V., Singh, S., Haritash, A. (2021). Evaluation of water quality and potential metal contamination in ecologically important Bhindawas bird sanctuary, India. Applied Water Science, 11(1).

Sharma, C. and Singh, S., (2013). Performance Evaluation of Sewage Treatment Plant Based On Advanced Aerobic Biological Filtration and Oxygenated Reactor (BIOFOR) Technology- A Case Study Of Capital City -Delhi, India. International Journal of Engineering Science and Innovative Technology (IJESIT), 2(4).

Sharma, P., (2013). A Comparative Study of Sewerage Treatment Plants with Different Technologies In The Vicinity Of Chandigarh City. IOSR Journal Of Environmental Science, Toxicology And Food Technology, 4(5), pp.113-121.

Shokeen, T., Singh, S. and Singh, G., (2020). Study on Adequacy of Functional Characteristics of a Typical Urban Waste Water Treatment Plant. International Journal of Advance Research and Innovation, 8(1), pp.26-29.

Showkat, U. and Najar, I., (2018). Study on the efficiency of sequential batch reactor (SBR)-based sewage treatment plant. Applied Water Science, 9(1).

Gupta S, S.K. Singh, Vishal Gandhi (2018) A Study on Sewage treatment \& Disposal in Delhi, International Journal of Advance Research \& Innovation (IJARI) Vol. 6, No. 2, pp 88-91

Singh S. and Deepika (2017) Assessment of water quality parameters of Bhalswa Lake in New Delhi, International Journal of Environmental Engineering - Inderscience, 9(1), 52-69. DOI: 10.1504/IJEE.2017.10008926

Singh S., Sachdeva H., Joon H., Narang M. (2020). Water Quality Assessment of a Water Body using Principal Component Analysis-Sanjay Lake, New Delhi, India. Asian Journal of Water, Environment and Pollution, 17(4) pp.23-29.

Singh, S., Gupta, S. and Gandhi, V., (2018). A study on Sewage Treatment and Disposal in Delhi. International Journal of Advance Research and Innovation, 6(2), pp.88-91.

Sundara K. Kumar, P. Sundara Kumar and Dr. M. J. Ratnakanth Babu, (2010). Performance evaluation of waste water treatment plant. International Journal of Engineering Science and Technology, Vol. 2(12), 7785-7796. 